\title{
The Lived Experiences in English Language Learning of the Thai Visually Impaired Students in the Inclusive Classroom
}

\author{
Buarattana Attachoo ${ }^{1} \&$ Pragasit Sitthitikul ${ }^{1}$ \\ ${ }^{1}$ Language Institute Thammasat University, Bangkok, Thailand \\ Correspondence: Buarattana Attachoo, Language Institute Thammasat University, Bangkok, Thailand.
}

Received: November 20, 2020

Accepted: December 21, 2020

Online Published: December 24, 2020

doi: $10.5539 /$ elt.v14n1p86

URL: https://doi.org/10.5539/elt.v14n1p86

\begin{abstract}
Under the light of educational equality, visually impaired students (VIS) have the right to improve their quality of life through educational achievement. Fortunately, policies and regulations encourage inclusive education to support all types of students including students with visual impairment. This means that the VIS are required to complete a compulsory educational system including studying English language in school and university levels. However, the mismatch between the objectives of the support policies and the practicality towards English Language Learning (ELL) among these students still exists in Thailand, and the difficulties in the ELL of the VIS remain uninvestigated. Hence, this study aims to explore the essence and meaning of ELL in an inclusive classroom derived from the perceptions of the VIS. To elicit the experiences from the participants, the phenomenological methodology was employed as the research design. The findings were drawn from nine students with visual impairment studying in an inclusive classroom setting. The data was collected from in-depth interviews and grouped into units of meaning or themes. The results showed that the essence of this study was shaped from both negative and positive aspects of ELL in an inclusive classroom, which can contribute to the VIS, practitioners, and administrative levels as guidance for future practices.
\end{abstract}

Keywords: English language learning, visually impaired students, inclusive education, phenomenological study

\section{Introduction}

\subsection{Introduction}

Education is the key to opportunity and it is for everyone, including students with disabilities. Education is also one of the vital factors to broaden their employment prospects and promote their social adaptation skills in order to improve their quality of life. Hence, no matter what type of disability a student may face, all students deserve the right to a full education. Equal to the sighted students, the VIS have the opportunity to broaden their future career path. In Thailand, according to the National Education Act of 1999, the curriculum aimed for equal education and regulated that all education levels 'shall aim at human development with desirable balance regarding knowledge, critical thinking, capability, virtue and social responsibility'. In higher education, it is obliged that the curricula 'shall emphasize academic development with priority given to higher professions and research for development of the bodies of knowledge and society' (National Education Act A. D., 1999). Despite the support policies officially provided by the government, the education path for the VIS who are studying at educational institutes has been found lacking compared to the whole population of people with visual impairment.

Apart from the limited educational opportunities, the VIS are required to study English. In Thailand, English is embedded as a mandatory language due to its status as a lingua franca and the goal of equipping their citizens to have expertise in using English. In terms of ELL of the VIS, there was another claim stating that blindness itself doesn't block their second language acquisition if the students are supported well enough (Praat \& Keil, 2003). This could be related to the concept of inclusive education involving modification in educational environments during the VIS's ELL, such as classroom, teaching aids, learning materials, and academic-related facilities. A number of researchers studied the challenges and the solutions, including educational supports contributing to the VIS, instructors, and administrators. However, the studies involving the VIS's education mainly investigated concepts of inclusive classrooms (Chumnan, 2006) relating to assistive technology such as using braille text, audio books, electronic readers, and media usage (Lersilp, Putthinoi, \& Chakpitak, 2015). This shows that although evidence of educational support has clearly appeared across Thailand, the difficulties in the area of the 
ELL of the VIS has not been deeply investigated, nor has the mismatch between the support policies and the concerning issues regarding the English language learning of the VIS.

\subsection{Significance of the Study}

This study mainly focuses on the lived experiences describing both encouragement and hardships towards the ELL of the VIS whose learning experiences are worthwhile to know (Mokiwa \& Phasha, 2012). Hence, other individuals with visual impairments will be able to explore the experiences of peers who share the same physical limitation. Regarding the situation where English is the compulsory subject and taught in inclusive classrooms with the sighted students, findings in this study not only reveal the VIS's lived experience, but also that of other practitioners around them. Hence, the data from this study will be ready-to-serve information as a basis for effective resolutions from the views of the VIS; and to provide research-based evidence for the administrative level on effective practices in VIS ELL as well as the defects that should be improved.

\subsection{Purposes of the Study}

In order to investigate in this area of ELL among VIS, phenomenological studies provide a way to obtain insightful and comprehensible information of the situation that might otherwise be overlooked. Hence, to collect the lived experience, the researcher decided to first explore the history of ELL of the VIS in order to understand the background that shaped the current situation. Secondly, the voices of the VIS describing learning English at different educational levels were also investigated. With consideration of the research problem and the purposes of this study, the main research question, along with sub-questions, were created in order to shape the research procedures and applied as a guide to reach the findings.

Main research question:

What are the lived experiences in English Language Learning of VIS in inclusive classrooms across Thailand?

\section{Sub-Questions:}

1. What is the English Language Learning background of VIS in inclusive classrooms?

2. What are the voices of the VIS towards their English Language Learning in the inclusive classroom?

The first question was designed to draw the picture of ELL in the past and how the inclusive classroom concept has been a part of the VIS' education background; the second question functioned as a guide to collect their experiences and feelings towards their current ELL and inclusive classroom experience.

\section{Literature Review}

\subsection{The Visually Impaired Students (VIS)}

In terms of a global definition of a person with visual impairment, the WHO provides a measurement of common visual acuity ranging from a person with low vision to a person with blindness. In Thailand, the Ministry of Social Development and Human Security (MSDHS, 2012) provides levels of visual acuity in two different categories: those with low vision and those who are blind. Additionally, the broad term of 'person with disability' can be found in the Education Provisions of Persons with Disabilities Act A. D. 2008 by integrating the educational concept into the definition. The term was defined as a person with restrictions on performing activities in daily life due to various types of impairment including sight impairment. Hence, in this study, the focal participants were students with visual impairment including those who have different levels and conditions of visual impairment ranging from low vision to totally blind.

\subsection{English Language Learning of Visually Impaired Students}

To achieve the goal of effective English language learning, related elements were classified into two major categories which are internal and external factors (Ellis, 2003). For the internal factors, the physical conditions of the learners, their attitudes towards the language, and motivation will be included; in contrast, the external factors consist of the environment, social setting, and pedagogical aspects. These factors tend to affect the second or foreign language learning of the sighted as well as the students with visual impairment. However, the most influencing factors which are sensory preference, motivation, and English skills will be pointed out as follows:

a. Sensory Preference: Basically, the VIS are unable to employ all sensory functions, so they apply the so-called 'perceptual compensation' as part of the extra-linguistic information used to acquire the second language. The perceptual compensation refers to interaction with their surroundings by using auditory and tactile senses to compensate for their visual restrictions (Rösler \& Neville, 2003), collectively recognized as the 'visual deprivation' (Bavelier \& Neville, 2002). Hence, the VIS unavoidably uses compensatory mechanisms to acquire 
language regardless of visual ability. In fact, in many cases, visual impairment may not prevent the VIS from learning foreign languages due to their increased efforts in terms of memory and listening skills, allowing them to reach the same level as sighted students (Pring, 2008). Thus, there might be challenges relating to the transformation of information. For example, the layout of foreign language textbooks is often complicated (Janae \& Jones, 2017) and is overloaded with design elements such as texts in columns, boxes and pictures.

b. English Skills: Obviously, difficulty or success in ELL for the blind students involved both internal and external factors at school and university level (Ellis, 2003). For reading skills, the learning material used most often in their English classes is Braille text which can only be read in linear sequence and influences their input in terms of limitations on applying reading skills such as skimming and scanning techniques. This could lead to a more time-consuming process in comparison with the sighted students (Lõvi, M., 2014). In fact, sequential reading restricts the VIS from going backwards to previous parts of the passage and makes it difficult to skip to the section that may contain useful information, and it might be impossible for the VIS to grasp the reading text in a holistic way (Hatton, 2014). In terms of listening skills for the VIS, they learn information from auditory input through reading audio books, so the nature of reading and listening skills could be found during reading as listening activities (Veispak, 2012). The characteristic of reading by hearing can also be explained by the integration between the comprehension in reading, listening and oral knowledge (Aryanti, 2014), as reading audio Braille text requires both reading and listening comprehension. Regarding English speaking skills, although the VIS seem to be expected that they should master English speaking skills due to the presumption on their hearing and speaking abilities (Visual Impairment: Its Effect on Cognitive Development and Behaviour, 2016), difficulties also appear when it comes to the ELL circumstances (Leong \& Ahmadi, 2017). For writing skills, students with visual impairment majorly rely on grammatical and vocabulary knowledge, and it has been mentioned as one of the hardest skills in ELL (Özer \& Cabaroğlu, 2018).

c. Learners' motivation and Teachers' attitudes: Crook and Schmidt (1989) pointed out that motivation towards language learning has been influenced by seven aspects including interest; perception; expectancy of success or failure; perception of rewards; overt decision to learn; persistent behavior; and high involvement. In terms of pedagogical aspects, motivation is also partly shaped by the instructional methods: a mastery-learning mode in which the students are encouraged to acquire intrinsic goal achievement (Brookfield \& Preskill, 2012). In the education system, the link between education and instruction is performed by the teacher who plays the role as a facilitator for students to reach their goal through the educational process (Karsli, 2007, p. 9). The positive attitudes increase the students' motivation, self-confidence and eventually lead to success in learning (Ulug et al., 2011). In contrast, negative attitudes could demotivate the students and might eventually lead to failures. Therefore, with the teachers' attitude and character, the students could shape their future from both memorable and tragic experiences.

\subsection{Inclusive Education for the VIS}

Not only developed countries, but also developing countries all over the world have shifted their educational standards through educational reforms, including the concepts of inclusive education for students with disabilities (NICHCY, 2012; Price, 2018). One of the advantages and primary goals of inclusive education is increasing social interaction between students with disabilities and their peers without disabilities to exchange their personal backgrounds in an academic setting, accept differences, and respect individuals' disabilities (Perles, 2010). On the contrary, regarding the concept of inclusion, Bateman \& Bateman (2020) argued that "full inclusion is not the best placement for all students" because "the general education classroom is typically not individualized" (p. 3). However, when the VIS study in inclusive settings, it is notable that the VIS have experienced major challenges in inclusive education elements consisting of learning materials; assistive technology; classroom accommodation; pedagogical aspect; and assessment as follows:

a. Learning Materials: Focusing on braille text, reading text in Braille is sequential and read letter-by-letter. Accordingly, such linear input creates challenges and limitations on how texts are presented because the graphical information must be transformed into a layout compatible with Braille. Moreover, the sequential flow also limits the VIS's reading ability due to being unable to read long chunks of words leading to a more time consuming and exhausting process (Castellano, 2005). Evidence shows that a skilled Braille reader is able to read at about half the speed of a good print reader (Nolan \& Kederis 1969; Savaiano et al., 2014; Trent \& Truan, 1997; Wormsley, 1996).

b. Assistive Technology: Several researchers have shown that the VIS compensate for visual loss by using assistive devices; however, reading speed can be delayed due to such assistive tools. For example, using slate and stylus while learning in class might extend difficulties as the VIS needed to focus on more than one task at 
the same time (Cowen \& Shepler, 2000; Gompel, Van Bon, \& Schreuder, 2004).

c. Classroom Accommodation and Pedagogical aspects: Generally, educational materials are presented in various types of visual formats such as posters, charts, diagrams, and videos. Thus, it might be more appropriate for the VIS to learn through alternate mediums or by using other functional senses such as tactile and hearing (AFB, 2012; NICHCY, 2012). Therefore, effective teachers of the VIS are encouraged to employ strategies that support the student's multisensory capabilities (visual, auditory, and tactile) in the classroom environment (AFB, 2012; Avaramidis \& Norwich, 2010; Rae et al., 2010). The modification of their educational environment is also important and influences how they learn, particularly in inclusive classroom settings (Cavanaugh, 2002).

d. Assessment: Generally, one of the challenges in assessment for all the learners is to complete a test within a limited period of time. However, this should be undertaken differently when it comes to the assessment for students with visual impairment. Especially in reading tests, the VIS usually spend considerably more time on reading Braille or the magnified text than the sighted students reading the standard print text.

\section{Method}

\subsection{Research Design}

Employing qualitative research methodology, researchers have an opportunity to experience 'the up-close information' from the perspective of those subjects who live through the problems in natural situations (Hatch, 2002; Creswell, 2014). In this study, qualitative research methodology allows the researcher to explore experiences and reflections in ELL through the unique characteristics and various backgrounds of the participants (Nunan \& Bailey, 2009). To obtain the authentic lived experiences of the VIS, phenomenological research methodology has been selected as the framework in this study (Moustakas, 1994; Marshall \& Rossman, 2011; Van Manen, 2016). The instrument utilized for data collection was in-depth interviews in order to gain a deep and rich set of data for analysis (Patton, 2002).

\subsection{Participants and Sampling Procedures}

In accordance with the qualitative research design, participants in this study were selected by using purposive sampling under the criterion-selecting strategy (Cohen et al., 2007). Criteria for the selection of the participants consisted of the following required characteristics: students who (1) are visually impaired; (2) are current students studying at high school and undergraduate levels; and (3) are studying in an inclusive setting. In order to gain wide ranging and authentic information, participants were selected from four regions across Thailand: Northern, Southern, North Eastern, and Central. After the research objectives and the data collection procedures were explained to the administrators for each institute, nine students volunteered to enroll in the interview as participants. Five secondary students were from four schools and four undergraduate students were from four universities. In order to ensure transparency on ethical issues, consent forms were signed by the participants before the face-to-face interviews were conducted.

Table 1. The Participant's Personal Information (School Level)

\begin{tabular}{llll}
\hline Students & Ages & Academic levels & Levels of Impairment \\
\hline ST1 & 18 & Grade 10 & Blind \\
ST3 & 19 & Grade 10 & Low vision \\
ST2 & 18 & Grade 11 & Blind \\
ST4 & 19 & Grade 11 & Low vision \\
ST5 & 21 & Grade 11 & Blind
\end{tabular}

Table 2. The Participant's Personal Information (University Level)

\begin{tabular}{llll}
\hline Students & Ages & Academic levels & Levels of impairment \\
\hline ST6 & 23 & 3rd year & Blind \\
ST7 & 24 & 1st year & Blind \\
ST8 & 21 & 2nd year & Low vision \\
ST9 & 25 & 2nd year & Blind \\
\hline
\end{tabular}




\subsection{Research Procedures}

The in-depth interview questions were created under the structure of Phenomenological Interviews, which were used as an instrument to elicit participants' lived experience under a relaxing and trusting atmosphere (Moustakas, 1994). The semi-structured interview was constructed according to Seidman's phenomenological interview model by grouping interview questions in to three sets aiming to elicit different aspects of the VIS's lived experience (Seidman, 2013) as shown in Appendix A. Firstly, question set one stimulates participants to recall their background focusing on historical and biographical details to activate the student's previous educational experience. Secondly, question set two aims to elicit information revealing behaviors, actions, and challenges regarding their recent lived experiences in ELL in an inclusive classroom. Lastly, question set three required a deeper consideration from the VIS by asking them to recall factors leading to the present point of their lives by including the key terms: 'expectations' and 'importance' in the interview questions leading to the meaning and understanding of their English language learning experience (Seidman, 2013).

The researcher began the data collection process by addressing the interview questions to each participant individually. During the interview process, the researcher was obliged to employ the concept of 'bracketing', which aims to get rid of researcher's subjectivity and avoid preconceptions (Moustakas, 1994). The interview sessions were conducted in Thai and lasted for one to two hours for each participant.

\subsection{Data Analysis}

The interview data was transcribed into verbatim description and reread by the VIS to ensure the data accuracy and followed by a phenomenological analysis. The phenomenological data analysis in this study followed the combination of data analysis processes introduced by Moustakas (1994) and Creswell (2014). Firstly, the transcribed information was thoroughly read, irrelevant information was removed, and equal value was assigned to all remaining statements. All relevant quotes and expressions were grouped as clusters called 'units of meaning or meaning units', which can be understood as the themes and subthemes. The explanation for each unit of meaning was built from participants' perceptions in a narrative format called textual description and was used as the foundation to be discussed as the structures of the phenomenon to reveal the essence of the lived experiences towards the ELL of the VIS.

\section{Research Findings}

After the statements from the transcription were studied and grouped into themes, the meaningful themes involving the English Language Learning of the VIS were presented ranging from the perceptions towards ELL; English language skills; and inclusive classrooms.

\subsection{Perceptions towards ELL}

When the VIS were asked to elaborate their experience on ELL during the interview, they automatically recalled their views and their feelings towards ELL, including how they see ELL as a subject matter. The responses were grouped according to negative perceptions; positive perceptions; perceptions towards transitional period; and the importance of ELL

Table 3. Theme and Subthemes for Perceptions towards ELL

\begin{tabular}{|c|c|c|}
\hline Theme & Subthemes & Aspects and Responses \\
\hline \multirow[t]{4}{*}{$\begin{array}{l}\text { Perceptions } \\
\text { towards ELL }\end{array}$} & Negative perceptions & $\begin{array}{l}\text { a. The relation between visual limitation and ELL } \\
\text { b. Feeling indifferent in auditory skills } \\
\text { c. Pedagogical aspects }\end{array}$ \\
\hline & Positive perceptions & $\begin{array}{l}\text { a. Being understood by their English teachers } \\
\text { b. The appropriateness in teaching style } \\
\text { c. Increasing motivation from the higher level of difficulties. }\end{array}$ \\
\hline & $\begin{array}{l}\text { The perceptions towards } \\
\text { transitional periods }\end{array}$ & $\begin{array}{l}\text { a. Increasing motivation } \\
\text { b. Higher self-confidence }\end{array}$ \\
\hline & The importance of ELL & $\begin{array}{l}\text { a. The un/necessity of ELL for the VIS } \\
\text { b. Acknowledged by their teachers } \\
\text { c. A tool to create equality } \\
\text { d. Benefits from learning English }\end{array}$ \\
\hline
\end{tabular}


The majority of VIS began their description with the negative feelings due to their visual limitation when comparing themselves to the sighted students leading to difficulties in ELL. They also linked their intrinsic condition to their challenges in ELL resulting in their low level of English ability. Additionally, there were statements insisting on disagreement with the presumption that visually impaired students generally had higher abilities in English listening and speaking skills than the sighted students.

ST7: "Among the senior blind students, some of them are inefficient in English which is strange why we are not good at English."

ST1: "People might think that when we cannot see things, our ears will perform better. I think that's not true. It is because we cannot see, so we rely more on our ears. We need to practice more of our auditory nerve and practice listening frequently."

Regarding teaching styles, there were a number of teaching approaches which caused the VIS to feel frustrated during classes. These instructional methods consisted of old teaching styles; the impracticality of the in-class exercises: the imbalance in content proportion; the overwhelming study with native teachers without preparation; and the negative reinforcement. The interview description showed that the feeling of dislike towards their English teacher was cultivated and cemented in their mindset resulting in the dislike towards studying English.

ST3: "I am not good at doing test practice in class. Teachers mostly bring the test practice in class and let the students complete the paper together. Doing this is good but I will forget it very soon and I don't understand the content. I will not bother with that anymore. Earlier, teachers would give us some take home exercises and discuss the answers in the following classes. But during this semester, the teachers will assign the reading tests and let the students finish the whole paper in class. For me, I am quite not good at doing this because my reading skill and my brain could not catch up with English and I could not complete the reading tests in time."

On the opposite side of negative perceptions, the VIS expressed a number of positive views by mentioning pleasant experiences in terms of being understood by their English teachers; inspiration due to the preference on English; appropriateness in teaching style; their motivation from higher level of difficulties. All the statements showed the VIS's positive feelings towards being understood by both their Thai and native English-speaking teachers.

ST1: "I like teacher who pays attention to me, especially, when the teacher knows that there is a blind student, and asks if we can catch up the lesson; or when the teacher give assignment, and know that there is a blind student in class, I do not have to do the same as other (sighted students). The teacher will allow me to do the other task instead."

Interestingly, the VIS further expressed their expectation towards instructional approaches in class through the final set of the interview questions. Explaining with the whole picture of how they wanted to be taught and treated in English classes, the VIS described that the ideal English class should be taught by having integration and balancing between the four main English skills with two-way communication and extra activities to reduce pressure. However, in cases where games are included in class, such games should not require using visual perception. Moreover, the VIS added that the teachers should teach along with an explanation on what is in the text or shown on screen, and the adjustment should be made to teaching materials in accordance with the learners.

ST4: "I want to learn knowledge and do activities just like in class taught by the native teacher, so that I will not be too stressed but can relax."

ST8: "I want the teacher to help magnify the font size and if there are videos such as conversation situations, I want the teacher to explain orally what happens in the videos. Also, play the game that uses only a little visual perception."

Another interesting aspect was their perceptions during their transitional period transferring from studying in a school for the blind located in their province to studying in the inclusive setting. One of the participants asserted that his self-confidence in ELL increased as he felt he was smarter after gaining more English knowledge and started to feel enjoyment after discovering that English was not as hard as he earlier thought. Additionally, another VIS stated they could gain higher motivation when facing harder lessons while only a few found certain difficulties between before and after moving to inclusive schools.

ST6: "I started to have fun with English, never get bored and can explain the lesson to my classmates which I had never done before in English subject. I feel that English is not that hard since I moved into the university."

Finally, the VIS were asked questions to provide reflection on the meaning of their ELL in their lives. The VIS 
expressed their feelings on whether ELL is necessary for them. Through their responses, it can be seen that although they have visual limitations, they feel that ELL was an unavoidable subject area that plays a very important role in their lives. All of the VIS highly valued ELL by mentioning their awareness of the importance of English as an international language and a tool to create equality for the blind.

ST6: "Being a blind or whoever, we are all humans. We need to live in this diverse society, so English is a tool which allows us to communicate with other people. If we think that we are blind, we don't have to learn English that is a huge mistake for limiting our opportunities in working and studying."

ST6: "[English] can help a lot. If we can use English, that means we have already removed the wall. Let's say, we are Thai and only speak Thai, and we leave Thailand to go overseas. We cannot communicate with anybody even for daily living, [so] we are unable to make it [without English]."

Lastly, the VIS addressed meaning towards ELL by presenting the importance of ELL for their future. The VIS unanimously agreed that learning English was necessary and could make their lives better.

\subsection{English Skills}

The responses towards the VIS's lived experiences with English skills directly involved the major areas of both receptive and productive skills. Generally, listening and speaking skills might be the skills that are assumed as the best skills that VIS could acquire and perform. However, the data from the interviews showed that the VIS mentioned all four English skills in terms of negative aspects such as their worst or most problematic skills; and positive aspects such as comprehension and being their best skills. The statements were grouped and discussed skill by skill as the following.

Table 4. Theme and Subthemes for English Skills

\begin{tabular}{|c|c|c|}
\hline Theme & Subthemes & Aspects and Responses \\
\hline \multirow[t]{4}{*}{$\begin{array}{l}\text { English } \\
\text { Skills }\end{array}$} & Writing & $\begin{array}{l}\text { a. The worst skill and most difficult as could not see the sentence structures } \\
\text { b. The most struggle skill with the unknown vocabulary } \\
\text { c. Being able to write only when learning in braille and could write only familiar } \\
\text { sentence }\end{array}$ \\
\hline & Reading & $\begin{array}{l}\text { a. Being unable to use skimming and scanning technique for audio book or during } \\
\text { the exam } \\
\text { b. Facing with the unknown vocabulary } \\
\text { c. The best skill }\end{array}$ \\
\hline & Speaking & $\begin{array}{l}\text { a. The worst skill as never practiced } \\
\text { b. Being unable to produce sentence correctly } \\
\text { c. Considering English speaking as their best skill or the skill they felt fine with. }\end{array}$ \\
\hline & Listening & $\begin{array}{l}\text { a. Recognizing the language without understanding } \\
\text { b. Being unable to catch the word } \\
\text { c. Failing to understand the content when teacher taught in English }\end{array}$ \\
\hline
\end{tabular}

From the responses, the VIS had negative perceptions of their writing ability based on grammar and vocabulary knowledge. In other words, they thought that they had low writing ability due to their limited grammatical ability and vocabulary knowledge. More than half of the VIS mentioned that writing was their worst and the most difficult skill as they could not see the sentence structures and were unable to create the whole sentences. However, one of the participants remarked that he was able to write in English if they learned from braille text with the restriction on writing only familiar sentences.

Not only in writing, but the lack of vocabulary knowledge and grammatical rules also hindered the VIS from achieving reading skills. The major problems for reading were also the lack of vocabulary size and knowledge, including spelling ability and limited understanding of grammatical rules. Especially during assessment in reading skills, the VIS were struggling with applying skimming and scanning techniques due to the linear direction of braille text reading. Consequently, this caused difficulties moving backward and forward to find the answers from the passage in the limited time.

For speaking skills, the findings seem to be in contrast with the common belief that the VIS would excel at speaking and listening skills. Most of the participants admitted that they did not tend to reply to conversation during the English class. Nonetheless, there was one VIS who mentioned that he was very good at speaking 
English when he was in secondary school and felt confident in his English speaking as his best skill. Interestingly, the participants, who mentioned that speaking seemed to be their worst skill, had never practiced in class and failed to produce sentences when they wanted to reply to the interlocutors.

Regarding listening skills, some of the VIS could recognize what they heard was the English language, but could not understand the meaning and were unable to catch the words in the conversation. Although challenges emerged through the experiences in listening skills, the VIS believed that they could make improvements in their listening if they kept doing listening exercises regularly.

\subsection{Inclusive Classrooms}

The study also investigated the inclusive settings that were considered as an integral part of the VIS education. The findings show how they understand or define the terms 'inclusive classroom' and their attitudes towards related elements of inclusive education. The statements were clustered into six themes which are (1) understanding the concept of inclusive classrooms; (2) learning materials; (3) assistive technology; (4) classroom accommodation; (5) classroom engagement; and (6) assessment.

Table 5. Theme and Subthemes for Inclusive Classrooms

\begin{tabular}{lll}
\hline & Subthemes & Aspects and Responses \\
\hline $\begin{array}{l}\text { Inclusive } \\
\text { Classroom }\end{array}$ & $\begin{array}{l}\text { Understanding the concept } \\
\text { of inclusive classrooms }\end{array}$ & $\begin{array}{l}\text { The aim to provide opportunities for the disabled to live in } \\
\text { society and allow the society to learn from the disabled. }\end{array}$ \\
Learning materials & $\begin{array}{l}\text { The difficulties in terms of the time-consuming process in } \\
\text { producing braille text }\end{array}$ \\
Assistive technology & $\begin{array}{l}\text { The impracticality of the assistive tools } \\
\text { Classroom accommodation }\end{array}$ & $\begin{array}{l}\text { Being blamed by her peers because she unintentionally } \\
\text { blocked the other students' sight }\end{array}$ \\
& Feeling satisfied when doing group tasks \\
Assessment & Adjustments provided with time extension
\end{tabular}

The VIS expressed their understanding of inclusive education objectives by asserting that studying inclusively aimed to provide opportunities for the disabled to live in society and allow the society to learn from the disabled.

ST2: "This might give the opportunity for the disabled to live in society. I think the blind students get the best chance compared to the deaf students. Well, I do not know about other types of the disabled students, but the blind student can come out and study with the sighted students."

Regarding the relevant factors in inclusive classrooms, responses of the VIS manifested opinions involving atmosphere in the classroom, as well as factors directly from their recent ELL involving the learning materials, either in their hands or provided by the teachers. The difficulties in terms of the time-consuming process in producing braille text were mentioned in the following.

ST6: "well, if we want to read an English book, there are so many steps to take. We have to bring the text to DSS and the staff will produce the braille version for us and that takes ages. After we get the braille version, we have to read through, so we will be slower than the class anyway."

Another aspect involving the assistive technology, the responses revealed that the tools might or might not be considered as functional as they were expected. Generally, the VIS seemed to use braille text as their textbook and use slate and stylus for note taking in class. However, these tools seemed to obstruct their ELL due to the impracticality while using in class.

ST7: "When I use slate and stylus, I need to write in codes and it is 4-5 dots for each code. This slows down my writing. While writing, I must listen to the teacher which I cannot follow up with, so I use a recorder to record the lesson and then type into my notebook as it lasts longer than writing in braille."

From the interview, the tools such as smartphones and internet started to be a part of their educational experiences in terms of assistive technologies to help them learn when there was no braille text and when they could not see written content on the board. Nonetheless, the VIS stated that in their early education lives, it was not only the lack of braille text and lack of modified information provided in advance, but there was also the prohibition of using smartphones in classes. 
For their experiences with classroom accommodation, there was one participant who had low vision and she was blamed by her peers due to accidentally blocking the sight of other students from what was written on the board. For the classroom engagement issue, all participants conveyed positive experiences as none of the VIS mentioned problems during the process while being recruited for the group tasks. The VIS expressed their satisfaction on being engaged in the classroom and assigned only the easy tasks such as finding information online.

ST7: "For group work, group members will make agreement on the tasks. Sometimes, I just wait for the others to assign me what to do. Well, I like giving presentations and I think others get tired of doing other things, and I don't have to write."

The final aspect in inclusive educational settings was the assessment which required modification in accordance with the VIS's condition. Apparently, most of the educational institutes were fully aware of the accommodations required in assessment and provided adequate adjustment appropriately for the VIS.

ST4: "There were sometimes the teacher told us that if we couldn't do it, we could change to do other things. For example, there was once the teacher gave us the animals'voices and we had to match the voices with the correct animals while the other students did the different test format."

\section{Discussion}

According to the research findings, despite the awareness of importance of ELL for the VIS in inclusive classrooms, the essences of the phenomenon revealed the inadequate supports in ELL and the issues of inappropriateness in instructional adjustment and learning materials in inclusive settings. Hence, in this part, the findings will be discussed in relation to the pedagogical aspects, English skills, and the situations in inclusive classrooms.

Generally, education provides knowledge and understanding to the learners while the instruction is the process to allow the learners to develop their ability and capacity (Karsli, 2007, p. 9). Hence, the instructions which are suitable for particular English skills could create the development in ELL among the VIS as a specific group of learners. In order to provide content and assistance in accordance with specific needs of the VIS, teachers who are responsible to teach this group of students should prioritize the appropriate accommodations towards pedagogical skills and attitudes (Nyoni, 2011). The appropriateness of instructional adjustment could be formed under the light of how important and necessary ELL is for the VIS. Although all of the VIS agreed that ELL is important and provides a number of benefits for them, the VIS should not be expected to master ELL due to the different levels of necessity and the function of English that they use in reality.

According to the difficulties in writing skills regarding grammatical issues, most of the VIS at the university level emphasized the benefits of using English braille text in ELL as they could learn sentence structures and positions of punctuation in sentences. This could imply that English braille use should be encouraged in learning writing skills. For reading skills, the struggle to employ skimming and scanning techniques lead to the difficulties in completing reading comprehension tasks during the exam as the VIS reads the passage differently from the sighted students and reading back and forth requires a large amount of time. In other words, this was linked to the implication that overloading memory of the VIS is required when they work on reading activities or exams leading to a more time-consuming process in comparison with the sighted students (Hatton, 2014). In terms of listening, although there have been several challenges emerging from limited vocabulary knowledge, hearing as reading plays an important role to help improve reading and listening comprehension for the VIS (Veispak, 2012).

To study English in an inclusive classroom, the information from the interviews could be discussed along with the actual practice. Regarding the learning materials, the decision whether to create the learning materials had to be evaluated under the condition of the expenses, time consumption, and worthiness. At school level, the support staff had to check whether the school already had the current braille text used in the English class or not. In the classroom, the assistive tools are used to fulfill the auditory ability of the VIS to perform the tasks (Castellano, 2005). However, not all the vis applied all the types of tools to facilitate their ELL. It depended on the functions of the technology in each tool. In the Thai context, the VIS did not own smartphones during their childhood; however, if they had, they were not allowed to use smartphones in class. Recently, the attitudes towards using smartphones and the internet for education in class seem to be more acceptable. Hence, the findings show that most of them used smartphones and the internet to help learning in class. Additionally, to ensure classroom engagement, the difficulties in both emotional and pedagogical concerns might have to be considered through the perspectives under the conditions of the impairment of the students. (Kocyigit \& Artar, 2015). The final issue is to figure out the challenges in assessments; collaboration with the special needs schools should be undertaken 
as more solid measures in terms of providing assistance are needed (OEC, 2006).

\section{Conclusion}

Through the phenomenological study notions, this study provided the lived experiences of the VIS regarding the interplay between their ELL and their educational lives in the inclusive classroom setting based on the themes or the units of meaning extracted from the in-depth interviews. The essence for this phenomenological study was depicted through their expectation towards the pedagogical aspect in ELL and the awareness of how meaningful ELL is for their future. More importantly, for disabled students with visual impairment, the findings could clearly illustrate the mismatch between the support policies in the equality of education and the deficits in practicality when it comes to English Language Learning. However, not all the aspects from the responses were negative perceptions. The VIS revealed their positive views of both ELL and the inclusive classroom concept in terms of their preferable instructional styles; factors which motivated their achievement in ELL; how they employed their language learning strategies; the English skills; and the accommodation in assessment. Therefore, the future research should be devoted to both investigation of the challenges and weaknesses of VIS ELL, and looking for supportive measures to affirm the strengths in ELL of the VIS.

\section{References}

American Foundation for the Blind. (2012). Expanded core curriculum (ECC) - Introduction: What is core curriculum. Retrieved from https://www.afb.org/info/programs-and-services/professional-development/expanded-core-curriculum-ecc/1 23

Aryanti, W. (2014). Difficulties in Learning English Faces by Visually Implied Students at Center of Language Development (P2B) in State Islamic University (UIN) Sunan Kalijaga. INKLUSI, 1(2). https://doi.org/10.14421/ijds.010204

Avramidis, E., \& Norwich, B. (2010). Teachers' attitudes towards integration/inclusion: A review of literature. European Journal of Special Needs Education, 17(2), 129-147. https://doi.org/10.1080/08856250210129056

Bateman, D., \& Bateman, C. (2002). What does a principal need to know about inclusion? Arlington, VA: ERIC Clearinghouse on Disabilities and Gifted/Education.

Bavelier, D., \& Neville, H. J. (2002). Cross-modal plasticity: Where and how? Nature Reviews Neuroscience, 3(6), 443-452. https://doi.org/10.1038/nrn848

Brookfield, S. D., \& Preskill, S. (2012). Discussion as a way of teaching: Tools and techniques for democratic classrooms. San Francisco, CA: John Wiley \& Sons.

Castellano, Carol. (2005). Making it work. Educating the Blind/Visually Impaired Student in Regular School. Greenwich, IAP Inc.

Cavanaugh, T. (2002). Assistive Technology and its Relationship with Instructional/ Educational Technology. Retrieved from https://www.unf.edu/ tcavanau/research/aet/index.htm

Chumnan, T. (2006). Social Behavior of Visually Impaired Student in an Inclusive School: A Case Study (Master Thesis). Retrieved from https://202.28.199.61/tdc/dccheck.php?Int_code=57\&RecId=27879\&obj_id=280914\&showmenu=no\&user id $=0$

Cohen, L., Manion, L., \& Morrison K. (2007). Research Methods in Education (6th ed.). London, UK: Routledge Falmer. https://doi.org/10.4324/9780203029053

Cowen, C., \& Shepler, R. (2000). Activities and games for teaching children to use magnifiers. In F. M. D'Andrea, F. M., \& Farrenkopf, C. (Eds.), Looking to learn: Promoting literacy for students with low vision (pp. 167-186). New York, NY: AFB Press.

Creswell, J. W. (2014). Research Design: Qualitative, Quantitative and Mixed Methods Approaches (4th ed.). Los Angeles: Sage Publications.

Crooked, G., \& Schmidt, R. (1989). Motivation: Reopening the Research Agenda. Language Learning, 41(4), 469-512. https://doi.org/10.1111/j.1467-1770.1991.tb00690.x

Ellis, R. (2003). Understanding Second Language Acquisition. Oxford: Oxford University Press.

Gardner, R. C., \& Lambert, W. E. (1959). Motivational variables in second-language acquisition. Canadian 
Journal of Psychology, 13(4), 266-272. https://doi.org/10.1037/h0083787

Gompel, M., Van Bon, W. H., \& Schreuder, R. (2004). Reading of children with low vision. Journal of Visual Impairment \& Blindness, 98, 77-89. https://doi.org/10.1177/0145482X0409800208

Hatch, JA. (2002). Doing Qualitative Research in Education Settings. Albany: State University of New York.

Hatton, D. D. (2014). Advancing the Education of Students with Visual Impairments Through Evidence-Based Practices. International Review of Research in Developmental Disabilities, 46, 1-22. https://doi.org/10.1016/b978-0-12-420039-5.00001-0

Johnson, J., \& Kerri, J. (2017). Educating Students with Visual Impairments in the General Education Setting. (Dissertations). Retrieved from https://aquila.usm.edu/dissertations/1337

Karsli, M. D. (2007). Egitim Bilimine Giris (Introduction to Education). Ankara: Pegem A.

Leong, L., \& Ahmadi, S. M. (2017). An Analysis of Factors Influencing Learners' English Speaking Skill. International Journal of Research in English Education, 2(1), 34-41. https://doi.org/10.18869/acadpub.ijree.2.1.34

Lersilp, S., Putthinoi, S., \& Chakpitak, N. (2015). Model of Providing Assistive Technologies in Special Education Schools. Global Journal of Health Science, 8(1), 36. https://doi.org/10.5539/gjhs.v8n1p36

Lõvi, M. (2014). Aspects of Teaching and Learning English as a Foreign Language in the Case of Blind and Visually Impaired Learners in Estonia (Doctoral dissertation). Retrieved from https://dspace.ut.ee/handle/10062/44002

Marshall, C., \& Rossman, G. B. (2011). Designing Qualitative Research (5th ed.). Thousand Oaks, CA: Sage Publications.

Mokiwa, S. A., \& Phasha, T. N. (2012). Using ICT at an Open Distance Learning (ODL) institution in South Africa: The learning experiences of students with visual impairments. Africa Education Review, 9(1), 136-151. https://doi.org/10.1080/18146627.2012.755286

Morelle, M., \& Tabane, R. (2016). Challenges experienced by learners with visual impairment in two mainstream primary schools in Klerksdorp (Unpublished master's thesis). Dr. Kenneth Kaunda District, South Africa.

Moustakas, C. (1994). Phenomenological research methods. Thousand Oaks, California: Sage Publications. https://doi.org/10.4135/9781412995658

National Dissemination Center for Children with Disabilities-NICHCY. (2012). Disability and Education Laws. Retrieved from https://nichcy.org/laws

National Education Act of B. E. 2542. (1991). Retrieved from https://asean.org/storage/2016/08/Thailand184.pdf

Nolan, C. Y., \& Kederis, C. J. (1969). Perceptual Factors in Braille Word Recognition. Research Series. New York, NY: American Foundation for the Blind.

Nunan, D., \& Bailey, K. M. (2009). Exploring second language classroom research: A comprehensive guide. Boston, MA: Heinle, Cengage Learning.

Nyoni, M., Marashe, J., \& Nyoni, T. (2011). Quest for inclusive education: The case of Pakame High School. Journal of Sustainable Development in Africa, 13(1). Retrieved from https://www.jsdafrica.com/Jsda/V13No1_Spring2011_A/PDF/The\%20Quest\%20for\%20Inclusive\%20Educ ation\%20\%28Nyoni,\%20Marashe,\%20Nyoni\%29.pdf

Özer, H. Z., \& Cabaroğlu, N. (2018). Teaching Vocabulary to Visually Impaired EFL Learners: A Small-Scale Study. Cukurova University Faculty of Education Journal, 47(1), 151-163. https://doi.org/10.14812/cuefd.379823

Patton, M. Q. (2002). Qualitative research and evaluation methods. Thousand Oaks, California: Sage.

Perles, K. (2010). Mainstreaming and inclusion: How are they different? Retrieved from https://www.brighthub.com/education/special/articles/66813.aspx

Praat, A., \& Keil, S. (2003). Defining Sight Difficulties for Education and Employment Research. British Journal of Visual Impairment, 21(2), 40-46. https://doi.org/10.1177/026461960302100202

Pring, L. (2008). Psychological characteristics of children with visual impairments: Learning memory and imagery. British Journal of Visual Impairment, 26, 159-169. https://doi.org/10.1177/0264619607088279 
Rae, H., Murray, G., \& McKenzie, K. (2010). Teachers' attitude towards mainstream schooling. Learning Disability Practice, 13(10). https://doi.org/10.7748/ldp2010.12.13.10.12.c8138

Röder, B., \& Neville, H. (2003). Developmental functional plasticity. Hand- book of Neuropsychology, 9, 231-270.

Savaiano, M. E., Compton, D. L., \& Hatton, D. D. (2014). Reading Comprehension for Braille Readers. International Review of Research in Developmental Disabilities, 46, 177-205. https://doi.org/10.1016/b978-0-12-420039-5.00004-6

Seidman, I. (2013). Interviewing as qualitative research: A guide for researchers in education and the social sciences. New York, NY: Teachers College Press.

Teaching the Blind Foreign Languages. (2015). Retrieved from https://www.robobraille.org/sites/default/files/resourcefiles/teaching_foreign_language_-_blind.pdf

Trent, S. D., \& Truan, M. B. (1997). Speed, accuracy and comprehension of adolescent Braille readers in a specialized school. Journal of Visual Impairments and Blindness, 91(5), 494-500. https://doi.org/10.1177/0145482X9709100509

Ulug, M., Ozden, M. S., \& Eryilmaz, A. (2011). The Effects of Teachers' Attitudes on Students' Personality and Performance. Procedia - Social and Behavioral Sciences, 30, 738-742. https://doi.org/10.1016/j.sbspro.2011.10.144

Van Manen, M. (1990). Researching lived experience. Albany, New York: State University of New York Press.

Veispak, A. (2012). Perceptual and Cognitive Underpinnings of Braille Reading (Doctoral dissertation). KU LEUVEN Faculty of Osychology and Educational Sciences, Belgium. https://doi.org/10.1016/j.ridd.2012.03.009

Visual Impairment: Its Effect on Cognitive Development and Behaviour. (2016). Retrieved from https://www.intellectualdisability.info/physical-health/articles/visual-impairment-its-effect-on-cognitive-dev elopment-and-behaviour

Wormsley, D. P. (1996). Reading rates of young braille-reading children. Journal of Visual Impairment and Blindness, 90(3), 278-282. https://doi.org/10.1177/0145482X9609000324 


\section{Appendix A}

Sample Questions for the Interview Guide for the Visually Impaired Students

Questions Set One

\begin{tabular}{ll}
\hline Item & Interview Questions \\
\hline 1. & Could you please tell me about yourself? \\
2. & What do you think is the difference (or challenge) growing up with a decreased ability \\
& to see? \\
3. & How does your current visual level affect your daily life and most significant in what \\
& aspect?
\end{tabular}

Questions Set Two

Item Interview Questions (English Language Learning)

1. Could you please tell me about your background on your English language learning?

2. If the visual limitation impacts your learning, please explain in both positive and negative ways.

3. What were the problems in learning English due to the visual limitation?

How did you handle with those situations?

4. During the study of English, what kind of instructional method or activity do you think help you learn the most?

\section{Questions Set Three}

\begin{tabular}{ll}
\hline Item & Interview Questions \\
\hline 1. & $\begin{array}{l}\text { As a VIS, how has your ELL been so far and how will English benefit you after the } \\
\text { graduation? }\end{array}$ \\
2. & What is your expectation on studying English in an inclusive classroom?
\end{tabular}

\section{Copyrights}

Copyright for this article is retained by the author(s), with first publication rights granted to the journal.

This is an open-access article distributed under the terms and conditions of the Creative Commons Attribution license (http://creativecommons.org/licenses/by/4.0/). 